\title{
Metastasectomy by video-assisted thoracic surgery (VATS)
}

\author{
Fabio J. Haddad, Jefferson L. Gross \\ Department of Thoracic Surgery, A.C. Camargo Cancer Center, São Paulo, SP, Brazil \\ Contributions: (I) Conception and design: All authors; (II) Administrative support: All authors; (III) Provision of study materials or patients: All \\ authors; (IV) Collection and assembly of data: All authors; (V) Data analysis and interpretation: All authors; (VI) Manuscript writing: All authors; (VII) \\ Final approval of manuscript: All authors. \\ Correspondence to: Fabio J. Haddad. Department of Thoracic Surgery, A.C. Camargo Cancer Center, R. Prof. Antônio Prudente, 211, São Paulo \\ 01509-010, SP, Brazil. Email: haddadfj@gmail.com.
}

\begin{abstract}
Metastasectomy is one of the most frequent procedures undertaken by thoracic surgeons, and its role has been validated by numerous retrospective studies. There are basic oncologic criteria for pulmonary metastasectomy, which include control of the primary cancer, no extrathoracic metastases, possibility of complete resection of the metastatic lung nodules, and patient good performance. With the progresses made in systemic treatment, a multidisciplinary discussion should be carried out before taking the patient for surgery. Video-assisted thoracic surgery (VATS) is already stablished as an important tool in the treatment of lung cancer, but its role in pulmonary metastasectomy has been a matter of debate. There are not controlled prospective data about the issue. However, in light of the retrospective data available, VATS can be used for metastasectomy, having in mind that complete resection of all metastatic disease is the main goal of this kind of surgery. VATS in also an interesting way to thoroughly stage the pleural cavity, the mediastinum, and the lung surface, before making a larger incision to palpate the lungs.
\end{abstract}

Keywords: Pulmonary metastases; video-assisted thoracic surgery (VATS); minimally invasive thoracic surgery; lung nodule

Received: 28 November 2018; Accepted: 16 December 2018; Published: 19 December 2018.

doi: 10.21037/jovs.2018.12.05

View this article at: http://dx.doi.org/10.21037/jovs.2018.12.05

\section{Introduction}

The lungs are a common site of metastatic spread from almost all types of extrathoracic solid malignancies. Its capillaries work as a filter, where malignant metastatic cells can get trapped and proliferate locally.

It is estimated that most patients with pulmonary metastases have widespread disease (75\%), and, traditionally, are not considered for surgical metastasectomy. On the other hand, there is a group of patients that will have disease confined to the lungs (25\%), and may benefit from local surgical therapy (1).

Furthermore, there are some malignancies that metastasize preferentially to the lungs, such as most sarcomas (2). Therefore, concentrating the effort on local control of the lung metastases may make oncologic sense, when the natural history of the disease of that specific patient gives you the right clues of its behavior.

The decision of operating a patient for metastasectomy is a complex one, and should be discussed in a multidisciplinary board, including surgeon, medical oncologist, radiation oncologist, pathologist, radiologist, pulmonologist, among others.

With the advent of computed tomography (CT), and its technological advances, more and more nodules can be detected in the preoperative period.

Thoracotomy with bi-manual palpation of the lung has been considered the gold standard method for pulmonary metastasectomy, since the fingers seem to find more nodules than expected with image studies.

Video-assisted thoracic surgery (VATS) emerged in the 1980 s as a less invasive alternative to thoracotomy for the treatment of lung cancer, and is considered nowadays an equivalent oncologic option, with less morbidity and 
Table 1 Selection criteria for candidates to lung metastasectomy

Primary tumor controlled or easily controllable

No extrathoracic disease (except for liver disease in colorectal cancer)

Lesions amenable to complete resection

Adequate pulmonary and systemic reserve for the procedure

No medical treatment more effective and/or with less toxicity than surgery

mortality in numerous comparative studies (3).

Accordingly, it was expected that VATS could also be applied in the context of pulmonary metastasectomy.

Our aim in this review is to show data that may take us to a better understanding of the role of VATS in lung metastasectomy.

\section{Historical perspective}

To our knowledge, the first resection of a single lung metastasis was reported in 1882 by Weinlechner, as an incidental finding when treating a chest wall sarcoma (4). During the next 50 years, elective surgical resection was performed in selected patients with single pulmonary nodules, and a long disease-free interval. Practice then was limited by the lack of specific imaging.

Larger series of cases were published in the early 70s, in patients with osteogenic sarcomas (5).

With the advent of CT, and better systemic treatment, metastasectomy gained proof of curative intent, especially in the management of childhood osteosarcomas. Fatal lung metastases occurred in $80 \%$ of these patients after treatment of the primary tumor, almost always with an amputation. In a series of 27 patients with lung metastases from osteosarcoma, complete resection of lung nodules resulted in control of the disease in $80 \%$ of the cases, and a $45 \% 5$-year survival rate.

Soon, the indications expanded to other primary sites, since new and more effective systemic treatment appeared to control micrometastatic disease, better selecting patients that would benefit from resection of the macroscopic lung disease.

After 1997, with the publication of the data from the International Registry of Pulmonary Metastases (6), that included 5,206 patients, more solid evidence of the benefit of this procedure was spread among multidisciplinary teams.

One interesting study by the MSKCC group (7), utilized patients as their own control group by submitting them to thoracotomy and manual palpation of the lung, after having VATS as their initial approach in a same operation. The results of this study showed that $56 \%$ of the metastases were not resected by VATS, when compared to thoracotomy.

For many years, VATS metastasectomy was considered a lesser surgery to treat lung metastases whatever the site of the primary cancer.

In more recent years, technology improved so that 1-mm slices could be performed in CT scans. New devices made the VATS procedure more effective and secure, such as better resolution of the videos, specific surgical material, and endoscopic surgical staplers. Nevertheless, VATS can give a better view of the pleural cavity, and provide a more thorough staging, before a thoracotomy is performed. In some instances, if the surgeon finds pleural implants during VATS, this would stop the surgeon to proceed with the resection.

\section{Basic principles and recommendations}

Adequate staging and physiologic evaluation of the patient are the basis before indicating resection of pulmonary metastases. Table 1 shows the most common criteria used to select patients.

Therefore, thorough image staging with positron emission tomography-CT (PET-CT), and local imaging of the chest and the primary-tumor, is indicated when selecting patients for pulmonary metastasectomy. In selected cases, a brain magnetic resonance imaging (MRI) is also indicated to exclude central nervous system (CNS) disease.

Other questions should be on the surgeon's mind before taking a patient to the operating room for pulmonary metastasectomy. What is the probability of a false-positive result, i.e., is this really metastatic disease? If single lesion, is this a new primary? If bilateral disease, what is the best approach, simultaneous or sequential resection? Should lymph nodes be removed during metastasectomy? What is the adequate margin? Is this patient curable? And finally, is VATS a good option for this case?

When dealing with a solitary lesion, one can be facing a benign nodule, or a second primary lung neoplasm. Histologic confirmation is recommended in this situation before any surgical procedure (8).

In regions where pulmonary granulomatous infections are prevalent, accessing the nodules with biopsies (i.e., transthoracic needle biopsy) may prevent other more invasive procedures to diagnose and treat benign disease. 


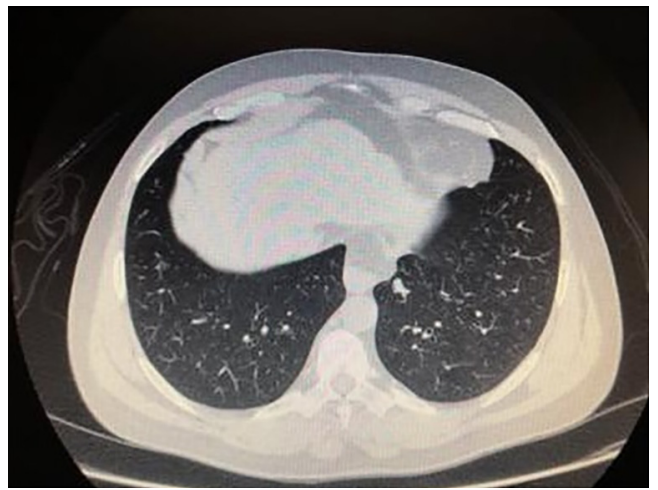

Figure 1 Chest-CT showing a solitary lung nodule difficult to biopsy in a patient with a previous soft-tissue sarcoma of the thigh resected 4 years earlier. This was a single metastasis and was resected by VATS. CT, computed tomography; VATS, videoassisted thoracic surgery.

In situations where the nodule is at a difficult location for biopsy, VATS can be an excellent tool to make the diagnosis with low morbidity, and consequently low mortality rates, besides having a therapeutic role as well (Figure 1).

Patients should be evaluated for their systemic and cardio-pulmonary reserve, and their surgical risk/benefit should be discussed with the multidisciplinary team, and with the patient.

In a recent publication by Welter and collaborators, histologic sections of pulmonary metastases were prospectively collected and analyzed. From 183 patients, 412 lung specimens were removed, containing 459 metastases. Local aggressiveness dissemination signs were studied. Local intrapulmonary recurrences were more significantly common when interstitial growth, pleural invasion, and safety margins $<7 \mathrm{~mm}$ were present. Also, the metastases showed histology-specific characteristics: sarcoma was more associated with pleural infiltration; colorectal metastases had more interstitial and aerogenous spread; and melanoma was related to perivascular growth and lymph vessel involvement (9). With respect to lymphadenectomy, there are no prospective studies proving it makes a difference in survival. However, when found, metastases to the hilar or mediastinal lymph nodes make the prognosis of the patient worse (10). This information may be of significance for the decision of adding systemic treatment, or when deciding for a re-resection after early recurrence of metastases in the lung, after an initial metastasectomy. Lymphadenectomy can be done by VATS, as it is done for primary non-smallcell lung cancer, in a safe and extensive way.

\section{Role of VATS metastasectomy}

The major criticism to the use of VATS for the treatment of pulmonary metastases is the lack of manual palpation of the lung, which could detect more nodules than initially visualized in the CT. Most of the retrospective data in lung metastasectomy shows that complete resection of all disease is an important factor for long term survival.

As mentioned earlier, in 1996, McCormack and colleagues (7) published a prospective trial where selected patients with one or two nodules were submitted to thoracoscopic resection and subsequently, in the same act, an open thoracotomy was performed and any other nodule found by lung palpation was resected. Ten out of 18 (56\%) patients had more malignant nodules than initially excised during VATS.

This study, in its conclusion, stated that VATS would only be useful for diagnostic purposes, and not for therapeutic metastasectomy.

Another prospective study by Cerfolio and coworkers, published in 2011, used 64-slice helical CT using 5-mm collimated cuts before submitting patients to thoracotomy for pulmonary metastasectomy. Overall, 51/152 (34\%) of patients had 57 pulmonary nodules found that were not imaged preoperatively, and 32/57 (56\%) of those were malignant. The authors say that the clinical significance of this finding is unknown, nor is the added morbidity of resecting benign nodules (11).

Despite those results, and with the improvement of imaging techniques and of surgical devices, VATS continued to be used at the discretion of the attending surgeon in many services.

On the contrary, Nakas et al. reported that VATSbased pulmonary metastasectomy was not inferior to the open approach, because 1-mm slice CT could detect those small nodules, and because of the expanded view of the camera in VATS, that could detect visceral and parietal pleural dissemination, avoiding a larger incision in this situation (12).

More recent data, although retrospective, showed that the surgical outcomes of pulmonary metastasectomy (overall survival and recurrence-free survival) were not different between VATS and open thoracotomy, regardless of what the primary tumor was (13).

In a metanalyses of observational studies, Meng et al. selected 8 studies which included 337 patients in the VATS group, and 485 in the open thoracotomy group. Although not statistically significant, survival was better in the VATS 


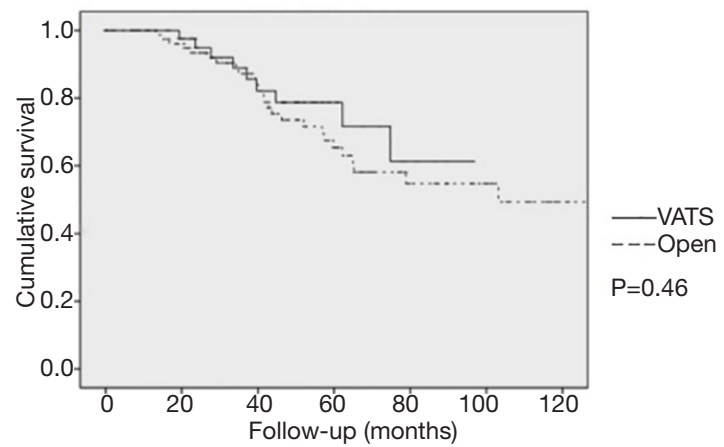

Figure 2 Overall survival curve for patients with pulmonary metastases from colorectal carcinomas submitted to metastasectomy by VATS or open surgery. VATS, video-assisted thoracic surgery.

group, and no difference was found in recurrence-free survival (14).

In another original article by the Metastatic Lung Tumor Study Group of Japan, specifically in colorectal metastases, Murakawa $e$ al. reported results that included 1,047 patients between 1999 and 2014 (15). Prognostic factors of overall survival were compared between thoracoscopic and open thoracotomy groups, after adjusting with propensity score matching. A difference between radiological tumor number and the resected tumor number (delta_num) was evaluated. In their analysis, VATS metastasectomy showed a better OS than the open approach (15).

At our center, we performed a retrospective analysis of 131 patients submitted to lung metastasectomy of colorectal primaries between 2003 and 2015 (data not published). Median number of metastases resected was 2 (1 to 5), and median follow-up was 42.8 months. Five-year OS was $79.4 \%$, and was $78.7 \%$ in the VATS group, and $58.2 \%$ in the open group in a univariate analysis $(\mathrm{P}=0.46)$ (Figure 2).

Other Brazilian authors and our group (Jefferson L.Gross) reported their results concerning lung metastasectomy in general, and specifically for sarcoma, melanoma and colorectal primaries, showing good 5-year survival. None of these papers, however, addressed the issue of VATS versus open surgery. Actually, most of the cases seem to have submitted do open surgery (16-20).

Higashiyama and coworkers suggest that, during VATS metastasectomy, curved staplers are useful in wedge resections of peripheral small nodules, maintaining a safe deep margin (13). Furthermore, the authors recommend, for the cases of metastases from colorectal cancer, the use of intraoperative lavage of the stapler cartridges to search for neoplastic cells, as they believe these tumors can spread through air spaces, and, in case of positive lavage, margins of the specimen should be reviewed.

\section{Conclusions}

The literature seems to support the use of VATS for metastasectomy, although it is still a matter of debate. The cases should be discussed by a multidisciplinary team of specialists before the surgical approach.

It sounds reasonable to use a minimally invasive approach to initially stage the pleural cavity, the mediastinum, and the lung surface, before performing a thoracotomy to manually palpate the lung.

Furthermore, if a 1-mm-slice recent chest CT shows only one or two nodules, in separate lobes, and close to the visceral pleural surface, this looks like a good case to complete the surgery by VATS.

If the surgeon, by any means, thinks he or she can do a better job by palpating the lung (multiple and deep nodules, close to each other), a hybrid approach can be performed, or even open thoracotomy, always having in mind that a complete resection of all disease is the main goal of this kind of operation.

In cases of metastases of carcinoma and melanoma, although also a matter of controversy, we recommend that hilar and mediastinal lymph nodes be, at least, sampled for better evaluating the patient's prognosis.

\section{Acknowledgments}

We would like to thank Ms. Ana Carolina Scintini Herbst, $\mathrm{RN}$, for helping with the preparation of the manuscript.

Funding: None.

\section{Footnote}

Provenance and Peer Review: This article was commissioned by the Guest Editors (Ricardo M. Terra and Paula A. Ugalde) for the series "Minimally Invasive Surgery - Robotics and VATS in Brazil" published in Fournal of Visualized Surgery. The article has undergone external peer review.

Conflicts of Interest: Both authors have completed the ICMJE uniform disclosure form (available at http://dx.doi. org/10.21037/jovs.2018.12.05). The series "Minimally Invasive Surgery - Robotics and VATS in Brazil" was commissioned by the editorial office without any funding or sponsorship. The authors have no other conflicts of interest 
to declare.

Ethical Statement: The authors are accountable for all aspects of the work in ensuring that questions related to the accuracy or integrity of any part of the work are appropriately investigated and resolved.

Open Access Statement: This is an Open Access article distributed in accordance with the Creative Commons Attribution-NonCommercial-NoDerivs 4.0 International License (CC BY-NC-ND 4.0), which permits the noncommercial replication and distribution of the article with the strict proviso that no changes or edits are made and the original work is properly cited (including links to both the formal publication through the relevant DOI and the license). See: https://creativecommons.org/licenses/by-nc-nd/4.0/.

\section{References}

1. Erhunmwunsee L, Tong BC. Preoperative Evaluation and Indications for Pulmonary Metastasetomy. Thorac Surg Clin 2016;26:7-12.

2. Rusch VW. Pulmonary metastasectomy. Current indications. Chest 1995;107:322S-31S.

3. Zhang R, Ferguson MK. Video-assisted versus open lobectomy in patients with compromised Lung Function: A literature review and meta-analysis. PLoS One 2015;10:e124512.

4. Pastorino U, Grunenwald D. Surgical resection of pulmonary metastases. In: Patterson GA, Pearson FG, Cooper JD, et al. Pearson's Thoracic and Esophageal Surgery, 3rd edition. Philadelphia: Churchill Livingstone, 2008.

5. Martini N, Huvos AG, Mike V, et al. Multiple pulmonary resections in the treatment of osteogenic sarcoma. Ann Thorac Surg 1971;12:271-80

6. Pastorino U, Buyse M, Friedel G, et al. The International Registry of Lung Metastases: Long-term results of lung metastasectomy: Prognostic analyses based on 5,206 cases. J Thorac Cardiovasc Surg 1997;113:37-49

7. McCormack PM, Bains MS, Begg CB et al. Role of videoassisted thoracic surgery in the treatment of pulmonary metastases: results of a prospective trial. Ann Thorac Surg 1996;62:213-6; discussion 216-7.

8. Caparica R, Mak MP, Rocha CH, et al. Pulmonary nodules in patients with nonpulmonary cancer: not always metastases. J Glob Oncol 2016;2:138-44.

9. Welter S, Arfanis E, Christoph D, et al. Growth patterns of pulmonary metastases: should we adjust resection techniques to primary histology and size? Eur J Cardiothorac Surg 2017;52:39-46.

10. Sihag S, Muniappan A. Lymph node dissection and pulmonary metastasectomy. Thorac Surg Clin 2016;26:315-23.

11. Cerfolio RJ, Bryant AS, McCarty TP, et al. A prospective study to determine the incidence of non-imaged malignant pulmonary nodules in patients who undergo metastasectomy by thoracotomy with lung palpation. Ann Thorac Surg 2011;91:1696-700; discussion 1700-1.

12. Nakas A, Klimatsidas MN, Entwisle J, et al. Video-assisted versus open pulmonary metastasectomy: the surgeon's finger or the radiologist's eye? Eur J Cardiothorac Surg 2009;36:469-74.

13. Higashiyama $M$, Tokunaga $T$, Nakagiri T, et al. Pulmonary metastasectomy: outcomes and issues according to the type of surgical resection. Gen Thorac Cardiovasc Surg 2015;63:320-30.

14. Meng D, Fu L, Wang L, et al. Video-assisted thoracoscopic surgery versus open thoracotomy in pulmonary metastasectomy: a meta-analysis of observational studies. Interact Cardiovasc Thorac Surg 2016;22:200-6.

15. Murakawa T, Sato H, Okumura S, et al. Thoracoscopic surgery versus open surgery for lung metastases of colorectal cancer: a multi-institutional retrospective analysis using propensity score adjustment. Eur J Cardiothorac Surg 2017;51:1157-63.

16. Younes RN, Gross JL, Taira AM, et al. Surgical resection of lung metastases: results from 529 patients. Clinics (Sao Paulo) 2009;64:535-41.

17. Younes RN, Fares AL, Gross JL. Pulmonary metastasectomy: a multivariate analysis of 440 patients undergoing complete resection. Interact Cardiovasc Thorac Surg 2012;14:156-61.

18. Younes RN, Abrao F, Gross J. Pulmonary metastasectomy for colorectal cancer: long-term survival and prognostic factors. Int J Surg 2013;11:244-8.

19. Younes R, Abrao FC, Gross J. Pulmonary metastasectomy for malignant melanoma: prognostic factors for long-term survival. Melanoma Res 2013;23:307-11.

20. Sardenberg RA, Figueiredo LP, Haddad FJ, et al. Pulmonary metastasectomy from soft tissue sarcomas. Clinics (Sao Paulo) 2010;65:871-6.

doi: 10.21037/jovs.2018.12.05

Cite this article as: Haddad FJ, Gross JL. Metastasectomy by video-assisted thoracic surgery (VATS). J Vis Surg 2018;4:247. 